\title{
Virtual setup in orthodontics: planning and evaluation
}

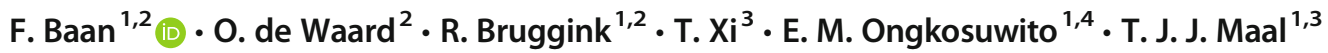

Received: 29 July 2019 / Accepted: 22 September 2019/Published online: 12 November 2019

(C) The Author(s) 2019

\begin{abstract}
Objectives The purpose of this study was to evaluate the clinical accuracy of virtual orthodontic setups by using a new CBCTbased approach.

Materials and methods Ten patients who underwent pre-surgical orthodontics were included in this study. Pre-treatment and presurgical cone-beam CT (CBCT) scans and digital dental models were available. The pre-treatment digital dental model was used to create an orthodontic virtual setup. The digital dental models were fused with the corresponding CBCT scans, and the two CBCT scans were aligned using voxel-based matching. Moving each individual tooth from the virtual setup to the final outcome allows the calculation of the accuracy of the virtual setup by using an iterative closest point algorithm. Differences between virtual setup and final outcome were recorded as well as the ICC between two observers.

Results The inter-observer variability showed a high level of agreement between the observers. The largest mean difference between observers was found in the cranial/caudal direction $(0.36 \pm 0.30 \mathrm{~mm})$ and the roll rotation $\left(1.54 \pm 0.98^{\circ}\right)$. Differences between the virtual setup and final outcome were small in the translational direction $(0.45 \pm 0.48 \mathrm{~mm})$. Rotational mean differences were larger with the pitch of the incisors $\left(0.00 \pm 7.97^{\circ}\right)$ and molars $\left(0.01 \pm 10.26^{\circ}\right)$ as largest difference. Excessive extrusion of all upper teeth and more anterior movement than planned were seen for both upper and lower arch. Lower molars showed less extrusion.

Clinical relevance The data of this study can be used to obtain more insight in the accuracy and achievability of orthodontic virtual setup. Tooth movement can now be studied in more details which can lead to new insights.
\end{abstract}

Keywords Orthodontics $\cdot$ CBCT $\cdot$ Orthognathic surgery $\cdot$ Tooth movement $\cdot$ Virtual setup

\section{Introduction}

Patients presenting with severe malocclusion and dentofacial deformities are commonly subjected to combined orthodontic treatment and orthognathic surgery [1-3]. Virtual surgical

F. Baan

frank.baan@radboudumc.nl

1 Radboudumc 3D Lab, Radboud University Medical Center, Geert Grooteplein Zuid 10, 6525, GA Nijmegen, The Netherlands

2 Department of Dentistry, Section of Orthodontics and Craniofacial Biology, Radboud University Medical Center, Philips van Leydenlaan 25, 6525, EX Nijmegen, The Netherlands

3 Department of Oral and Maxillofacial Surgery, Radboud University Medical Center, Geert Grooteplein Zuid 10, 6525, GA Nijmegen, The Netherlands

4 Amalia Cleft and Craniofacial Centre, Radboud University Medical Centre, Geert Grooteplein Zuid 10, 6525, GA

Nijmegen, The Netherlands planning is a frequently used tool in orthognathic surgery. In this virtual environment, the surgeon can perform osteotomies, simulate different treatment strategies, and predict the facial profile after surgery [4-6]. Based on this virtual planning, surgical splints can be fabricated and used to position the jaws in the planned positions during surgery. Predictable post-operative outcome can be obtained in this way $[4,7,8]$.

While orthognathic surgery is virtually planned, taking the smallest details into account [4-6], this is rarely the case for the pre-surgical orthodontic treatment [9]. An optimal pre-surgical orthodontic treatment is essential to decompensate the dental arches, as dental misalignment can mask the underlying skeletal discrepancies and hinder the required surgical jaw movements [10-12]. Properly performed orthodontic decompensation facilitates the surgeon in obtaining a stable post-operative occlusion and optimal post-operative result [12].

As a result of the fast advancements in digital dentistry, three-dimensional (3D) virtual setup in orthodontics is an emerging technology. 3D virtual setup is able to simulate the 
orthodontic treatment by segmenting individual teeth and moving each individual tooth to its desired position. Up till now, 3D virtual setup is mainly used as a diagnostic tool to confirm, modify, or reject a suggested treatment plan. The individual need for inter-proximal reduction or dental extractions to solve crowding or dental protrusion can be predicted [9]. In addition, the 3D virtual setup has the potential to be used as a therapeutic tool to execute the orthodontic treatment with use of indirect bonding trays, individually customized wires, and thermoplastic aligners [13]. According to a previous study, virtual setups are as accurate as manual setups [14]. A virtual setup may also be preferred over a conventional setup as it has a high repeatability and is overall more efficient [9, 15-17].

With the introduction of $3 \mathrm{D}$ virtual setups, it is possible to integrate the orthodontic setup with the virtual orthognathic planning. Falter et al. [18] revealed that $13.5 \%$ of the orthognathic patients underwent a different surgical operation than was originally planned at the start of the treatment. Planning ahead of the orthodontic treatment should theoretically lead to less ad hoc treatment plan changes and a more predictable treatment outcome.

Despite the general consensus on the advantages the virtual setup has over the conventional setup, a limited amount of research has been conducted regarding the achievability of the virtual setup [15, 19-21]. In previous studies, the discrepancy between the final tooth position and the planned position has been assessed. However, all those studies are lacking accurate $3 \mathrm{D}$ information because of the use of best-fit algorithms to match the final outcome with the planned virtual setup. This makes the virtual setup less valuable especially in the vertical dimension as the best-fit method diminishes the reference to the face of the patient. To our knowledge, few studies are available with assessment of the virtual setup in relation to the skull of the patient in 3D.

To make a proper comparison between the virtual orthodontic setup and the final outcome, this study proposes a new method which uses CBCT for aligning both dental arches at different timestamps. This new method provides the movement for each tooth individually in all dimensions. The aim of the study was to assess the newly developed CBCT-based approach and the clinical accuracy of the virtual pre-surgical orthodontic setup.

\section{Materials and Methods}

\section{Participants}

Ten patients who were treated for their dentofacial deformities between 2014 and 2016 were selected for this retrospective study. All patients were treated with combined orthodontic treatment and orthognathic surgery. All patients received bimaxillary osteotomies. Initial severity was not considered during selection. All patients were treated in the academic clinic by orthodontic residents under supervision of one orthodontist. Inclusion criteria were the availability of two CBCT scans and two 3D models of the dental arches, one prior to orthodontic treatment and one prior to orthognathic surgery. Patients with less than 24 teeth or teeth with occlusal stops and patients with orofacial clefts and craniofacial anomalies were excluded from this study. Anonymization and deidentification of all patient data was performed prior to analysis. This research was conducted in accordance with the Helsinki declaration with regard to research in human subjects. Ethical approval was waived by the local institutional review board (2016-2690). All patients signed an informed consent at the start of treatment.

\section{Image acquisition}

Two CBCT scans were acquired for each patient. One CBCT scan was acquired before the start of the orthodontic treatment, and the second CBCT scan was taken 4 weeks prior to orthognathic surgery. On both occasions, an extended-height CBCT scan was acquired (FOV, $16 \times 22 \mathrm{~cm}$; scanning time, 2 $\times 20 \mathrm{~s}$; voxel size, $0.4 \mathrm{~mm}$; 3D Imaging System, Imaging Sciences International Inc, Hatfield, PA, USA). Directly after each CBCT scan, a 3D digital model was acquired of the dental arches, by using either digitized plaster models or intra-oral scans of the dental arches.

\section{Creating the orthodontic virtual setup}

OrthoAnalyzer (3Shape, Copenhagen, Denmark) was used to perform a virtual orthodontic setup on the pre-treatment dental model. The orthodontist, who created the virtual setups, had access to all patients' records and the treatment plan but was blinded to the final outcome of orthodontic treatment. Creating a virtual setup starts with the determination of arch form and tooth axis (Fig. 1a). Each of the individual teeth were semi-automatically segmented using the OrthoAnalyzer software [9] (Fig. 1b).

After this stage, the teeth were manually repositioned to their ideal position according to the treatment plan and key principles of occlusion: correct molar relationship (in final jaw position), correct crown angulation, correct crown inclination, no rotations, no interdental spaces, an appropriate plane of occlusion, correct interproximal contact points, a normal overjet and overbite (1-4 mm) [22], and aligned midlines with respect to the facial midline (Fig. 1c). The original mandibular inter-canine distances were respected and acted as a guide for obtaining the final maxillary arch widths and shape. The virtual setup was made also considering the treatment factors like the anatomical boundaries, wire play, arch form, and the expected torque loss. 
Fig. 1 Overview of the virtual setup for the maxilla. a Semiautomatic determination of the border of each tooth. $\mathbf{b}$ Segmentation of each tooth. c Virtual setup is created by displacing each individual tooth to create a harmonious arch

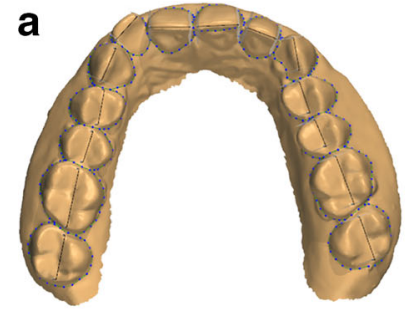

b

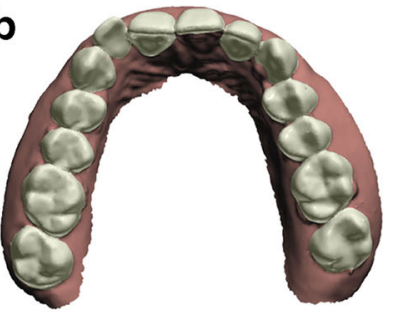

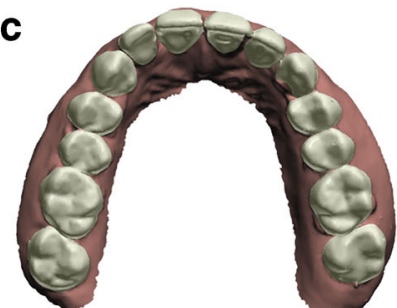

\section{Treatment evaluation}

Six steps were carried out to evaluate the difference between the digital dental models at the start of the treatment, the virtual setup, and the final outcome for each tooth independently. Steps 1 till 3 were all performed by one observer as these are all validated steps using validated algorithms [23]. Steps 4 and 5 were performed by two observers as these steps utilize the newly created CBCT-based approach in the MED software.

\section{Step 1: registration of the pre-treatment dental model with the pre-treatment $\mathrm{CBCT}$}

The digitized pre-treatment dental models were superimposed onto the pre-treatment CBCT by using IPS CaseDesigner (KLS Martin Group, Tuttlingen Germany). Three corresponding points on both the pre-treatment $\mathrm{CBCT}$ and the pretreatment dental model were placed allowing the software to perform the registration of the digital model with the CBCT (Fig. 2). The 3D-augmented skull model with dentition was then imported into the in-house-created software, MED, which is based on Open Inventor ${ }^{\circledR}$ (version 9.9.10, Houston, USA).

\section{Step 2: registration of the pre-surgery dental model with the pre-surgery $\mathrm{CBCT}$}

IPS CaseDesigner was used for the superimposition of the presurgery dental model to the pre-surgery CBCT. After registration, the 3D-rendered skull with dentition was imported into the MED software.

\section{Step 3: registration of the pre-surgery $\mathrm{CBCT}$ to the pre-treatment $\mathrm{CBCT}$}

The pre-treatment $\mathrm{CBCT}$ with the aligned dental models and the pre-surgery $\mathrm{CBCT}$ with the aligned corresponding dental models were imported into the MED software. Voxel-based matching (VBM) was used to register pre-surgery $\mathrm{CBCT}$ to the pretreatment CBCT. The stable regions of the anterior cranial base, zygomatic arches, and forehead were used for VBM [23, 24].
Fig. 2 Matching of intra-oral scan in the CBCT scan. a The CBCT scan with three dental landmarks. b The intra-oral scan with the same dental landmarks as in the CBCT. $\mathbf{c}$ Cross-section of the result of the fusion. $\mathbf{d}$ Final result showing the fusion of the intraoral scan with the CBCT

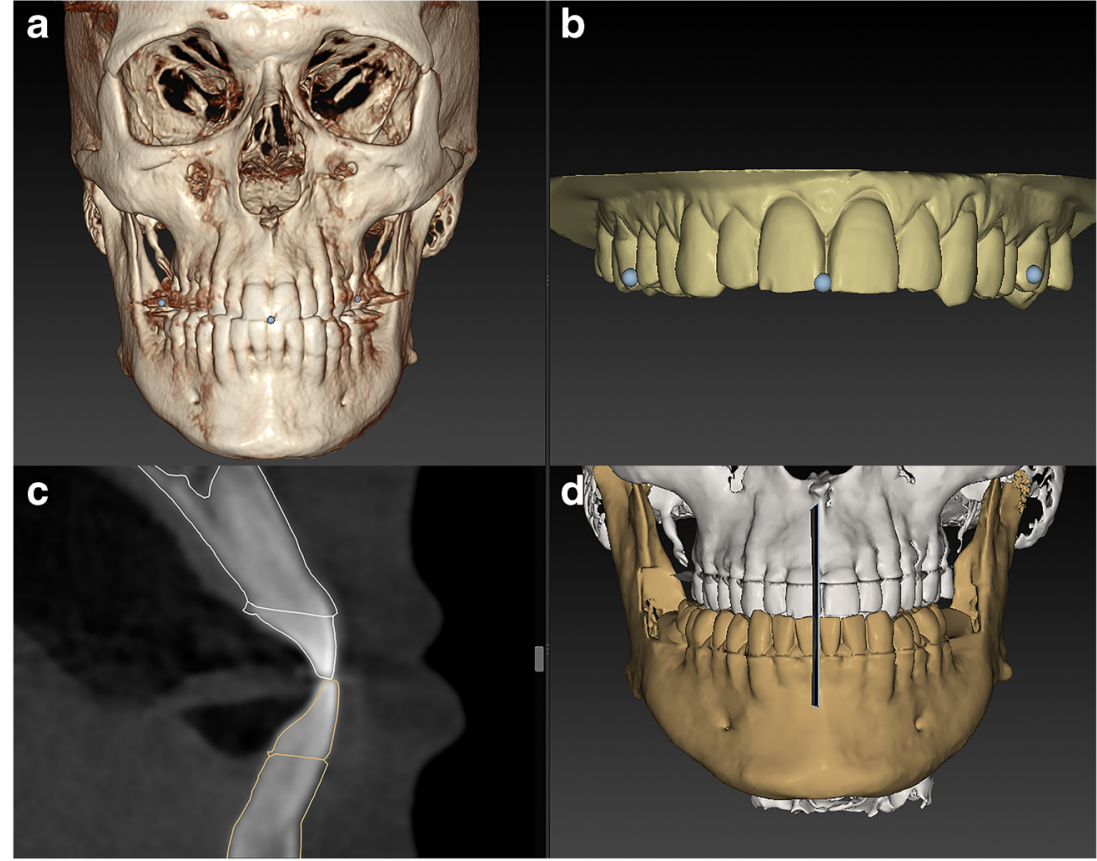


Step 4: calculate movement between pre-treatment dental model and the virtual setup

The virtual setup as well as each segmented tooth was exported from the OrthoAnalyzer software towards Standard Tessellation Language (STL) files and imported into the MED software (Fig. 3a). The MED software creates an individual coordinate system $(x-, y$-, and $z$-axes) for each tooth. Using a 3D surface-based matching (SBM) algorithm [25] (Iterative Closest Point), each individual tooth is rotated and translated from the pre-treatment dental model to the virtual setup (Fig. 3b). All translations and rotations were recorded and saved for each individual tooth. The 6 degrees of freedom (DOF) are computed: yaw, roll, and pitch (Fig. 4), and the left to right translations (LR), anterior to posterior translations (AP), and cranial to caudal translations $(\mathrm{CC})$.

\section{Step 5: calculate movement per tooth between virtual setup and pre-surgical dental model}

The pre-surgical dental model was imported into the MED software (Fig. 3c). For each individual tooth, the movement from virtual setup to the pre-surgical dental model was performed in the same way as the calculation of the movement

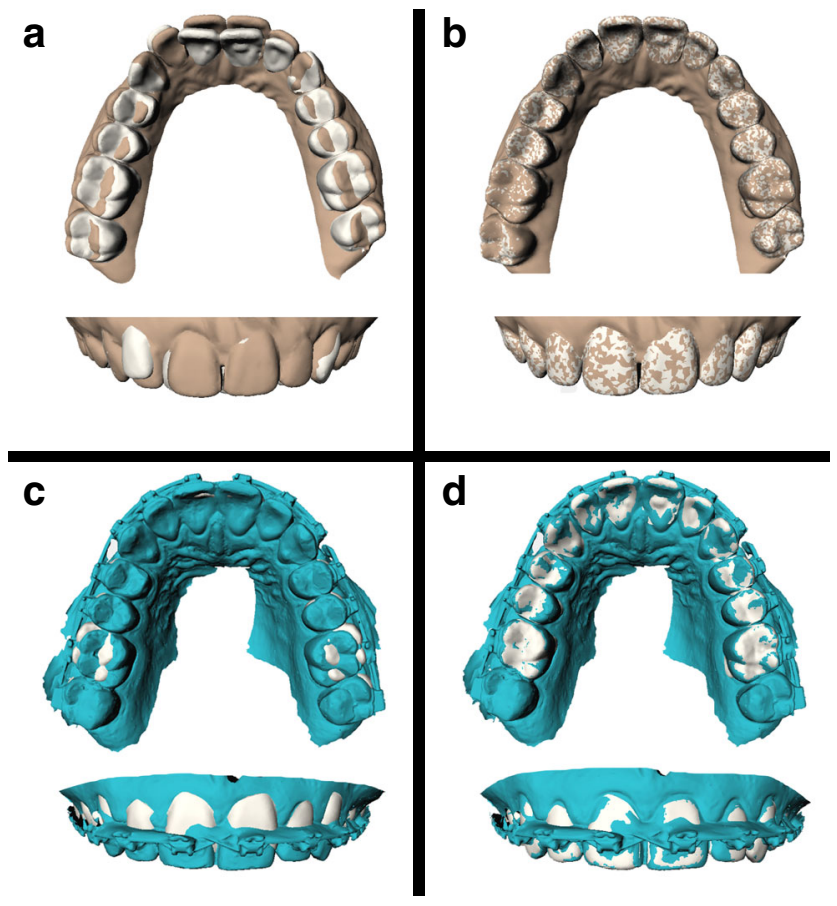

Fig. 3 Overview of the different steps to calculate the difference between the virtual setup and the final outcome for the maxilla. For the mandible, the same steps are required. a In brown, the pre-treatment dental arch, and in white, the segmented teeth of the virtual setup. b Each individual tooth is matched onto the virtual setup. Translations and rotations for each tooth are recorded. $\mathbf{c}$ In blue, the final outcome, and in white, the teeth of the virtual setup. d Each individual tooth (white) is matched onto the final outcome (blue). The translations and rotations are recorded and the difference between the virtual setup and final outcome can be calculated

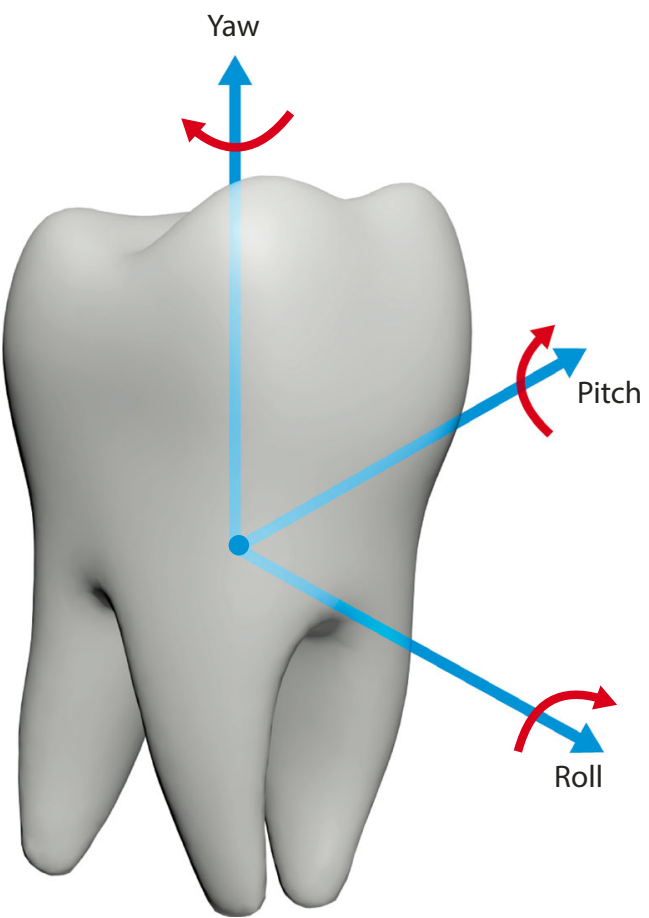

Fig. 4 The rotation axis pitch, roll, and yaw shown in a molar

from the pre-treatment dental model to the virtual setup (Fig. 3d). Again, the 6 DOF per tooth were recorded and saved.

\section{Clinical validation and evaluation}

Using the MED software, all translations and rotations of individual teeth were recorded and imported in IBM SPSS software, version 24.0.1 (IBM Corp., Armonk, NY, USA). The reliability of the method was evaluated by calculating the mean difference and standard deviations for all parameters from pre-treatment tooth position to virtual setup and from virtual setup to the pre-surgery tooth position between both observers. To assess the correlation between observers, the intra-class correlation coefficient was calculated for steps 4 and 5. The differences in final outcome between the two observers were taken as a measure for the reproducibility of the method with the developed in-house-created software.

\section{Results}

Six females (mean age, 25.8 years; range, 17-40 years) and four males (mean age, 27.5 years; range, 17-45 years) with eight skeletal class II profiles and two class III profiles were enrolled into this study. Of these 10 patients, 20 jaws, 10 maxillae, and 10 mandibles were included in this study. Four patients had pre-molar extractions. The 20 jaws had in total 237 teeth, 117 teeth in the maxilla and 120 in the mandible (Table 1). Five patients underwent a surgically assisted rapid maxillary expansion before the orthodontic treatment. 
Table 1 Number of elements included in the study

Upper teeth Number of elements Lower teeth Number of elements

\begin{tabular}{llll}
\hline Incisors & 38 & Incisors & 40 \\
Canine & 20 & Canine & 20 \\
Premolars & 33 & Premolars & 37 \\
Molars & 40 & Molars & 38 \\
\hline
\end{tabular}

\section{Validation of the registration method}

Two observers performed steps 4 and 5 to investigate the interobserver reliability for the tooth movements. The mean translational and rotational movements of each tooth were recorded for both observers, and the differences are displayed in Tables 2 (T0 to virtual setup) and 3 (Virtual setup to T1) (Table 3). The inter-observer ICC values are displayed in Table 4. The inter-observer ICCs show a high level of agreement between the observers. The largest mean difference between observers in the translational direction was found in the cranial/caudal direction $(0.36 \pm 0.30 \mathrm{~mm})$. For the rotational directions, the roll showed the largest difference between the observers $\left(1.54 \pm 0.98^{\circ}\right)$.

\section{Clinical accuracy of the virtual setup}

The differences of each individual tooth type, between the virtual setup and the final outcome, are listed in Table 5. All mean differences for translations are smaller than $0.45 \mathrm{~mm}$ with standard deviations from 0.48 to $1.14 \mathrm{~mm}$. For rotations, all mean differences are smaller than $3.04^{\circ}$ with standard deviations from $3.31^{\circ}$ to $10.26^{\circ}$.

Remarkable differences between the final tooth positions and virtual setups regarding translations were the excessive extrusion of all upper teeth and more anterior movement of molars in the upper and lower arches. Lower molars showed less extrusion whereas lower premolars showed relatively more extrusion than expected compared with the virtual setup. Lower canines and premolars underwent more lateral movement.

Regarding rotations, all teeth in the upper and lower arches displayed a more mesial rotation (yaw) in the post-treatment position, with exception of the upper molars. Lower premolars showed a remarkable higher buccal crown torque (roll, $3.04 \pm 4.87^{\circ}$ ). Upper pre-molars (pitch, $1.30 \pm 3.31^{\circ}$ ) and lower canines (pitch, $-1.16 \pm 5.24^{\circ}$ ) and molars (pitch, $1.69 \pm 4.37^{\circ}$ ) have more backward crown rotation ("negative tip") in the final outcome. Large variations are found for the pitch in upper incisors and molars with standard deviations of $7.79^{\circ}$ and $10.26^{\circ}$, respectively.

\section{Discussion}

Patients with severe malocclusions and jaw deformities require a treatment combination of orthodontic treatment and orthognathic surgery. Preparation of orthognathic surgery is currently completely performed digitally with the use of $\mathrm{CBCT}$ and special software simulating treatment to predict the final outcome [4]. Post-operatively, it is also possible to analyze whether the surgery has been performed according to the virtual 3D planning [26]. For orthodontic treatment, these $3 \mathrm{D}$ treatment simulations and post-treatment analyses are not commonly used [9]. When a virtual setup is used, it is easier to decide which movements such as leveling or asymmetric movements should be corrected in the orthodontic phase or in the surgery phase, and thereby potentially shorten the duration of the combined treatment.

To be able to perform post-orthodontic analyses, 3D information of dental models is required at the beginning and end
Table 2 Rotational and translation differences between observers for tooth movement from $\mathrm{T} 0$ to virtual setup

\begin{tabular}{|c|c|c|c|c|c|c|}
\hline & \multicolumn{3}{|l|}{ Rotations } & \multicolumn{3}{|l|}{ Translations } \\
\hline & $\begin{array}{l}\text { Pitch (deg) } \\
\text { Mean } \pm \text { SD }\end{array}$ & $\begin{array}{l}\text { Roll }(\mathrm{deg}) \\
\text { Mean } \pm \text { SD }\end{array}$ & $\begin{array}{l}\text { Yaw (deg) } \\
\text { Mean } \pm \text { SD }\end{array}$ & $\begin{array}{l}\mathrm{LR}(\mathrm{mm}) \\
\text { Mean } \pm \mathrm{SD}\end{array}$ & $\begin{array}{l}\mathrm{AP}(\mathrm{mm}) \\
\mathrm{Mean} \pm \mathrm{SD}\end{array}$ & $\begin{array}{l}\mathrm{CC}(\mathrm{mm}) \\
\mathrm{Mean} \pm \mathrm{SD}\end{array}$ \\
\hline \multicolumn{7}{|l|}{ Upper teeth } \\
\hline Incisors & $0.04 \pm 0.10$ & $0.04 \pm 0.08$ & $0.06 \pm 0.12$ & $0.01 \pm 0.03$ & $0.00 \pm 0.01$ & $0.02 \pm 0.07$ \\
\hline Canine & $0.03 \pm 0.06$ & $0.04 \pm 0.10$ & $0.06 \pm 0.14$ & $0.00 \pm 0.00$ & $0.00 \pm 0.00$ & $0.00 \pm 0.00$ \\
\hline Premolar & $0.04 \pm 0.09$ & $0.04 \pm 0.14$ & $0.04 \pm 0.10$ & $0.00 \pm 0.01$ & $0.01 \pm 0.03$ & $0.00 \pm 0.01$ \\
\hline Molar & $0.00 \pm 0.01$ & $0.01 \pm 0.01$ & $0.00 \pm 0.01$ & $0.00 \pm 0.00$ & $0.00 \pm 0.00$ & $0.00 \pm 0.00$ \\
\hline \multicolumn{7}{|c|}{ Lower teeth } \\
\hline Incisors & $0.04 \pm 0.07$ & $0.07 \pm 0.11$ & $0.06 \pm 0.10$ & $0.01 \pm 0.02$ & $0.00 \pm 0.02$ & $0.00 \pm 0.01$ \\
\hline Canine & $0.08 \pm 0.10$ & $0.07 \pm 0.11$ & $0.10 \pm 0.15$ & $0.01 \pm 0.03$ & $0.00 \pm 0.01$ & $0.00 \pm 0.01$ \\
\hline Premolar & $0.04 \pm 0.08$ & $0.03 \pm 0.07$ & $0.04 \pm 0.08$ & $0.02 \pm 0.06$ & $0.01 \pm 0.03$ & $0.01 \pm 0.04$ \\
\hline Molar & $0.06 \pm 0.13$ & $0.03 \pm 0.09$ & $0.08 \pm 0.17$ & $0.02 \pm 0.04$ & $0.02 \pm 0.04$ & $0.03 \pm 0.06$ \\
\hline
\end{tabular}

$L R$, left/right; $A P$, anterior/posterior; $C C$, cranial/caudal; $S D$, standard deviation 
Table 3 Rotational and translation differences between observers for tooth movement from virtual setup to $\mathrm{T} 1$

\begin{tabular}{|c|c|c|c|c|c|c|}
\hline & \multicolumn{3}{|l|}{ Rotations } & \multicolumn{3}{|l|}{ Translations } \\
\hline & $\begin{array}{l}\text { Pitch }(\text { deg) } \\
\text { Mean } \pm \text { SD }\end{array}$ & $\begin{array}{l}\text { Roll }(\text { deg }) \\
\text { Mean } \pm \text { SD }\end{array}$ & $\begin{array}{l}\text { Yaw }(\mathrm{deg}) \\
\text { Mean } \pm \text { SD }\end{array}$ & $\begin{array}{l}\mathrm{LR}(\mathrm{mm}) \\
\text { Mean } \pm \mathrm{SD}\end{array}$ & $\begin{array}{l}\mathrm{AP}(\mathrm{mm}) \\
\mathrm{Mean} \pm \mathrm{SD}\end{array}$ & $\begin{array}{l}\mathrm{CC}(\mathrm{mm}) \\
\mathrm{Mean} \pm \mathrm{SD}\end{array}$ \\
\hline \multicolumn{7}{|c|}{ Upper teeth } \\
\hline Incisors & $1.22 \pm 0.44$ & $1.54 \pm 0.98$ & $1.17 \pm 0.73$ & $0.18 \pm 0.17$ & $0.35 \pm 0.27$ & $0.36 \pm 0.30$ \\
\hline Canine & $1.17 \pm 0.71$ & $1.19 \pm 0.78$ & $1.27 \pm 0.88$ & $0.25 \pm 0.25$ & $0.35 \pm 0.30$ & $0.33 \pm 0.30$ \\
\hline Premolar & $1.17 \pm 0.73$ & $1.02 \pm 0.66$ & $1.44 \pm 0.82$ & $0.30 \pm 0.28$ & $0.34 \pm 0.28$ & $0.30 \pm 0.29$ \\
\hline Molar & $1.03 \pm 0.65$ & $1.05 \pm 0.72$ & $1.25 \pm 0.89$ & $0.27 \pm 0.24$ & $0.31 \pm 0.29$ & $0.29 \pm 0.25$ \\
\hline \multicolumn{7}{|c|}{ Lower teeth } \\
\hline Incisors & $1.16 \pm 0.65$ & $1.30 \pm 0.83$ & $1.39 \pm 1.05$ & $0.20 \pm 0.17$ & $0.23 \pm 0.21$ & $0.21 \pm 0.21$ \\
\hline Canine & $1.26 \pm 0.78$ & $1.27 \pm 0.93$ & $1.14 \pm 0.70$ & $0.16 \pm 0.23$ & $0.14 \pm 0.17$ & $0.18 \pm 0.19$ \\
\hline Premolar & $1.00 \pm 0.68$ & $1.22 \pm 0.95$ & $1.30 \pm 0.83$ & $0.15 \pm 0.15$ & $0.19 \pm 0.17$ & $0.27 \pm 0.26$ \\
\hline Molar & $0.98 \pm 0.73$ & $1.33 \pm 1.05$ & $1.22 \pm 0.82$ & $0.18 \pm 0.15$ & $0.14 \pm 0.13$ & $0.22 \pm 0.25$ \\
\hline
\end{tabular}

$L R$, left/right; $A P$, anterior/posterior; $C C$, cranial/caudal; $S D$, standard deviation of the orthodontic treatment. Superimposition of the dental models is necessary to evaluate spatial changes in time. For maxillary dental models, superimposition can be performed accurately by utilizing stable reference areas like the palatal rugae [27-29]. However, when large tooth movements are performed, for example, in cases of premolar extractions, the palatal rugae might not be stable. Also, dental changes in the vertical dimension may alter the palatal rugae, making it unfeasible for superimposition [30]. In contrast with the maxilla, no stable anatomical structures in the mandible are present for the superimposition of lower dental models at different moments of the treatment $[31,32]$. Especially, when all teeth are being displaced, superimposition of the lower dental arch is very challenging.

Therefore, the authors proposed a new method to analyze the final outcome of orthodontic treatment using CBCT imaging and dental models. By using CBCT data and digital dental models, the position of the dental arch and each individual tooth can be analyzed with reference to the position and orientation in the face and skull of the patient.

The results of the current study show a high level of agreement between observers. The largest mean difference between observers is $0.36 \pm 0.30 \mathrm{~mm}$. For the rotational directions, the roll showed the largest difference between the observers (1.54 $\left.\pm 0.98^{\circ}\right)$. The results also show a high level of agreement between observers for the comparison between the pretreatment dental models, virtual setups, and pre-surgery dental models as shown by the found mean differences and correlations. The intra-class coefficient was larger for the teeth movement from virtual setup to final outcome compared with the pre-treatment to virtual setup movement. A possible explanation for this is the presence of brackets and wires on the presurgical models which reduces the matching area during the surface-based matching. Another potential error is the occurrence of dental wear during the orthodontic treatment which could also influence the individual tooth matching procedure. These relatively large differences are according to literature assessed as clinically irrelevant for diagnostic purposes. The high level of inter-observer agreement is in accordance with previous studies assessing setup accuracy and aligner accuracy $[14,33]$. Studies comparing the accuracy of matching different types of digital models considered mean differences between linear measurements from 0.44 to $0.62 \mathrm{~mm}$ clinically irrelevant [34-36].

\section{Virtual setup versus final outcome}

An underestimation of the extrusion of all upper teeth and the leveling of the curve of Spee in the lower arch during the orthodontic treatment was seen. A possible reason for the extrusion of the upper incisors in the final outcome is the previous performed SARME procedure and subsequent closing of the diastema in $50 \%$ of the patients. Xi et al. [37] found an increase of the dental show by a mean of $2.2 \pm 2.0 \mathrm{~mm}$ following SARME. Because most orthodontic mechanics without absolute anchorage are extrusive in nature [38], there should have been anticipated more for that.

A potential explanation for the differences between the virtual set-ups and the final outcomes is the "patient-related factor." For example, compliance problems like undesirable debonds of brackets or wire bends due to chewing could have led to tooth aligning errors. The final outcome showed relatively more forward migration of molars, probably the result of more anchorage loss than expected. Also, lower premolar torque and lateral movement are more pronounced in the final outcome. The lower transversal dimensions were respected in the virtual setup, while during treatment this was probably less respected. Furthermore, more leveling of the curve of Spee in the lower arch occurred than expected, probably because of an 
Table 4 The inter-observer Intraclass Correlation Coefficient for both teeth movements from T0 to virtual setup (VS) and VS to $\mathrm{T} 1$

\begin{tabular}{|c|c|c|c|c|c|c|c|c|c|c|c|c|}
\hline & \multicolumn{6}{|c|}{ Rotations } & \multicolumn{6}{|c|}{ Translations } \\
\hline & \multicolumn{2}{|c|}{$\operatorname{Pitch}\left({ }^{\circ}\right)$} & \multicolumn{2}{|c|}{ Roll $\left(^{\circ}\right)$} & \multicolumn{2}{|c|}{ Yaw $\left({ }^{\circ}\right)$} & \multicolumn{2}{|c|}{$\mathrm{LR}(\mathrm{mm})$} & \multicolumn{2}{|c|}{$\mathrm{AP}(\mathrm{mm})$} & \multicolumn{2}{|c|}{$\mathrm{CC}(\mathrm{mm})$} \\
\hline & VS & $\mathrm{T} 1$ & VS & $\mathrm{T} 1$ & VS & $\mathrm{T} 1$ & VS & $\mathrm{T} 1$ & VS & $\mathrm{T} 1$ & VS & $\mathrm{T} 1$ \\
\hline \multicolumn{13}{|l|}{ Upper teeth } \\
\hline Incisors & 1.00 & 0.99 & 1.00 & 0.95 & 1.00 & 0.96 & 1.00 & 0.89 & 1.00 & 0.86 & 1.00 & 0.90 \\
\hline Canine & 1.00 & 0.96 & 1.00 & 0.97 & 1.00 & 0.95 & 1.00 & 0.92 & 1.00 & 0.88 & 1.00 & 0.89 \\
\hline Premolars & 1.00 & 0.92 & 0.99 & 0.97 & 1.00 & 0.96 & 1.00 & 0.93 & 1.00 & 0.86 & 1.00 & 0.90 \\
\hline Molars & 1.00 & 0.99 & 1.00 & 0.97 & 1.00 & 0.93 & 1.00 & 0.82 & 1.00 & 0.92 & 1.00 & 0.93 \\
\hline \multicolumn{13}{|l|}{ Lower teeth } \\
\hline Incisors & 1.00 & 0.93 & 0.99 & 0.93 & 1.00 & 0.94 & 1.00 & 0.88 & 1.00 & 0.81 & 1.00 & 0.88 \\
\hline Canine & 1.00 & 0.96 & 1.00 & 0.93 & 1.00 & 0.96 & 1.00 & 0.89 & 1.00 & 0.92 & 1.00 & 0.93 \\
\hline Premolars & 1.00 & 0.97 & 1.00 & 0.97 & 1.00 & 0.95 & 1.00 & 0.95 & 1.00 & 0.91 & 1.00 & 0.90 \\
\hline Molars & 1.00 & 0.96 & 1.00 & 0.92 & 1.00 & 0.94 & 1.00 & 0.89 & 1.00 & 0.92 & 1.00 & 0.95 \\
\hline
\end{tabular}

$L R$, left/right; $A P$, anterior/posterior; $C C$, cranial/caudal; $S D$, standard deviation underestimation of the leveling capacities of the orthodontic treatment in the lower arch.

Grauer et al. [13] and Pauls [39] used superimposition of (virtual) setups and final models to evaluate the Incognito system. Grauer et al. [13] found mean differences generally less than $1 \mathrm{~mm}$ and $4^{\circ}$ for discrepancies between position and rotation of individual teeth between setup and final outcome using a closest point algorithm without using 3D information. The study of Pauls [39] showed deviations in rotations of less than $4.6^{\circ}$ and in translations under $0.5 \mathrm{~mm}$ for the frontal teeth. They concluded that the appliances are accurate in achieving the planning. Our study found smaller mean
Table 5 The differences between the virtual setups and the final outcomes

\begin{tabular}{|c|c|c|c|c|c|c|}
\hline & \multicolumn{3}{|l|}{ Rotations } & \multicolumn{3}{|l|}{ Translations } \\
\hline & $\begin{array}{l}\operatorname{Pitch}^{\mathrm{a}}(\mathrm{deg}) \\
\text { Mean } \pm \text { SD }\end{array}$ & $\begin{array}{l}\operatorname{Roll}^{\mathrm{b}}(\mathrm{deg}) \\
\text { Mean } \pm \text { SD }\end{array}$ & $\begin{array}{l}\text { Yaw }^{c}(\mathrm{deg}) \\
\text { Mean } \pm \text { SD }\end{array}$ & $\begin{array}{l}X: L^{d}(m m) \\
\text { Mean } \pm S D\end{array}$ & $\begin{array}{l}\mathrm{Y}: \mathrm{AP}^{\mathrm{e}}(\mathrm{mm}) \\
\mathrm{Mean} \pm \mathrm{SD}\end{array}$ & $\begin{array}{l}\mathrm{Z}: \mathrm{CC}^{\mathrm{f}}(\mathrm{mm}) \\
\text { Mean } \pm \mathrm{SD}\end{array}$ \\
\hline \multicolumn{7}{|l|}{ Upper teeth } \\
\hline Incisors & $0.00 \pm 7.97$ & $-0.24 \pm 4.70$ & $-2.43 \pm 4.90$ & $-0.02 \pm 0.84$ & $0.15 \pm 0.81$ & $-0.27 \pm 0.80$ \\
\hline Canine & $-0.39 \pm 4.66$ & $-1.25 \pm 4.54$ & $-2.96 \pm 4.44$ & $0.04 \pm 0.94$ & $0.27 \pm 0.90$ & $-0.16 \pm 0.79$ \\
\hline Premolars & $1.30 \pm 3.31$ & $0.47 \pm 4.86$ & $-1.24 \pm 5.57$ & $-0.09 \pm 1.14$ & $0.34 \pm 0.95$ & $-0.28 \pm 0.68$ \\
\hline Molars & $0.01 \pm 10.26$ & $0.80 \pm 4.58$ & $0.68 \pm 4.08$ & $0.05 \pm 0.81$ & $-0.31 \pm 1.11$ & $-0.45 \pm 0.90$ \\
\hline \multicolumn{7}{|l|}{ Lower teeth } \\
\hline Incisors & $0.11 \pm 4.16$ & $-0.35 \pm 4.25$ & $-1.34 \pm 4.98$ & $0.24 \pm 0.62$ & $-0.11 \pm 0.57$ & $0.00 \pm 0.60$ \\
\hline Canine & $-1.16 \pm 5.24$ & $-0.04 \pm 4.51$ & $-1.54 \pm 5.10$ & $0.35 \pm 0.55$ & $-0.02 \pm 0.55$ & $0.06 \pm 0.61$ \\
\hline Premolars & $0.16 \pm 5.24$ & $3.04 \pm 4.87$ & $-1.67 \pm 5.12$ & $0.41 \pm 0.62$ & $0.02 \pm 0.48$ & $0.22 \pm 0.84$ \\
\hline Molars & $-1.69 \pm 4.37$ & $0.34 \pm 4.07$ & $-0.57 \pm 4.16$ & $0.11 \pm 0.54$ & $-0.23 \pm 0.57$ & $-0.24 \pm 0.71$ \\
\hline
\end{tabular}

$L R$, left/right; $A P$, anterior/posterior; $C C$, cranial/caudal; $S D$, standard deviation

${ }^{a}$ A positive value means an anti-clockwise rotation compared with the virtual setup; a negative value means a clockwise rotation compared with the virtual setup

${ }^{\mathrm{b}}$ A positive value means an anti-clockwise rotation around the horizontal axis compared with the virtual setup; a negative value means a clockwise rotation around the horizontal axis compared with the virtual setup

${ }^{\mathrm{c}}$ A positive value means an anti-clockwise rotation around the vertical axis compared with the virtual setup; a negative value means a clockwise rotation around the vertical axis compared with the virtual setup

${ }^{\mathrm{d}}$ A positive value means that the tooth was positioned more buccal compared with the virtual setup; a negative value means that the tooth was positioned more lingual compared with the virtual setup

${ }^{\mathrm{e}}$ A positive value means that the tooth was positioned more posteriorly than planned; a negative value means that the tooth was positioned more anteriorly than planned

${ }^{\mathrm{f}}$ A positive value means that the tooth was displaced more cranially compared with the virtual setup; a negative value means that the tooth was displaced more cranially compared with the virtual setup 
differences and less variation between setup and final outcome with use of 3D information provided by the CBCT scans. Muller-Hartwich et al. [15] used SureSmile technology to align the teeth and a best-fit algorithm to match setup and final outcome founded median deviations of $0.19-0.21 \mathrm{~mm}$ based on translational movements and $1.77-3.04^{\circ}$ based on rotational movements.

The authors concluded that these differences are clinically irrelevant, and the virtual setups can be implemented in the clinic; they concluded this based on the results and conclusions in other comparable studies. Larson et al. [40] using the Suresmile system evaluated the customization of wires. As in the present study, they calculated the differences between virtual setups and the final outcome. For posterior teeth, they did not always succeed in meeting their stated goal of keeping translations below $\pm 0.5 \mathrm{~mm}$ and rotations below $2^{\circ}$. They found mean differences up to $-0.52 \mathrm{~mm}$ and $4.68^{\circ}$. The threshold values in the study of Larson [40] were selected as they represent accepted professional standards as used in the American Board of Orthodontics (ABO) objective grading system.

Important differences between above-mentioned studies and the current study is that no customized system is used in this study, and all studies above describe positional deviations of teeth relative to each other in contradiction with our study in which we describe positional changes of the teeth relative to the jawbone. All studies found more accuracy in the frontal than in the posterior teeth which is in accordance to our findings.

The heterogeneity of the patient selection could be a source of error. For example, the closure of extractions spaces could potentially lead to undesirable side effects, i.e., deepening of curve of Spee or tipping, inducing more difficulties to achieve well-decompensated dental arches (less-predictable result). The limited number of cases in this study is a complicating factor in drawing strong conclusions on the influence of extractions or the SARME procedure on the accuracy of the virtual setups. It is important to notice that only one observer made the virtual setups. More research is needed to investigate the reproducibility of the production of the $3 \mathrm{D}$ virtual setups between and within observers and with a bigger patient sample to rule out the influence of different treatment plans.

\section{Conclusion}

This new method is an accurate tool to investigate the dental changes in all 6 degrees of freedom in relation to the face. It shows a good reliability with a high level of agreement between observers. The treatment outcome can be virtually simulated using the virtual setup. However, more research with more patients is needed to discover the effect of orthodontic treatment on the transversal and vertical dimensions, especially in premolar extraction cases and patients who received a SARME procedure to be able to make a more accurate $3 \mathrm{D}$ virtual setup and inform our patients with a higher level of predictability at the start of treatment.

Author contributions F. Baan contributed to the conception, design, data digitalization, data analysis, interpretation, and drafted and critically revised the manuscript. O. de Waard contributed to the conception, design, data digitalization, data analysis, interpretation, and drafted and critically revised the manuscript. R. Bruggink contributed to the design of the in house made software and drafted and critically revised the manuscript. T. $\mathrm{Xi}$ contributed to the data interpretation and critically revised the manuscript. E.M. Ongkosuwito, and T.J.J. Maal contributed to the conception, design, data interpretation, and critically revised the manuscript. All authors gave final approval and agree to be accountable for all aspects of the work.

\section{Compliance with ethical standards}

Conflict of interest The authors declare that they have no conflict of interest.

Ethical approval The present study was approved by the Research Ethics Committee (CMO), Region Arnhem/Nijmegen, The Netherlands (2016-2690). All procedures performed in studies involving human participants were in accordance with the ethical standards of the Institutional Review Board and with the 1964 Helsinki declaration and its later amendments or comparable ethical standards.

Informed consent For this type of study, formal consent is not required.

Open Access This article is distributed under the terms of the Creative Commons Attribution 4.0 International License (http:// creativecommons.org/licenses/by/4.0/), which permits unrestricted use, distribution, and reproduction in any medium, provided you give appropriate credit to the original author(s) and the source, provide a link to the Creative Commons license, and indicate if changes were made.

\section{References}

1. Fonseca R, Baily L, Proffit W (2000) Patient selection for orthognathic surgery. Saunders, Philadelphia

2. Proothi M, Drew SJ, Sachs SA (2010) Motivating factors for patients undergoing orthognathic surgery evaluation. J Oral Maxillofac Surg 68(7):1555-1559

3. Finlay PM, Atkinson JM, Moos KF (1995) Orthognathic surgery: patient expectations; psychological profile and satisfaction with outcome. Br J Oral Maxillofac Surg 33(1):9-14

4. Stokbro K, Aagaard E, Torkov P, Bell RB, Thygesen T (2014) Virtual planning in orthognathic surgery. Int J Oral Maxillofac Surg 43(8):957-965

5. Nadjmi N, Mollemans W, Daelemans A, Van Hemelen G, Schutyser F, Bergé S (2010) Virtual occlusion in planning orthognathic surgical procedures. Int J Oral Maxillofac Surg 39(5):457-462

6. Swennen GRJ, Mollemans W, Schutyser F (2009) Threedimensional treatment planning of orthognathic surgery in the era of virtual imaging. J Oral Maxillofac Surg 67(10):2080-2092 
7. Wu T-Y, Lin H-H, Lo L-J, Ho C-T (2017) Postoperative outcomes of two- and three-dimensional planning in orthognathic surgery: a comparative study. J Plast Reconstr Aesthet Surg 70(8):1101-1111

8. Lin H-H, Chang H-W, Wang C-H, Kim SG, Lo L-J (2015) Threedimensional computer-assisted orthognathic surgery. Ann Plast Surg 74:S118-S126

9. Camardella LT, Rothier EKC, Vilella OV, Ongkosuwito EM, Breuning KH (2016) Virtual setup: application in orthodontic practice. J. Orofac. Orthop./Fortschritte der Kieferorthopädie 77(6): 409-419

10. Strohl AM, Vitkus L (2017) Surgical orthodontics. Curr Opin Otolaryngol Head Neck Surg 25(4):332-336

11. Huang CS, Orthodontic YC (2015) Orthodontic principles and guidelines for the surgery-first approach to orthognathic surgery. Int J Oral Maxillofac Surg 44(12):1457-1462

12. Wirthlin JO, Shetye PR (2013) Orthodontist's role in orthognathic surgery. Semin Plast Surg 27(3):137-144

13. Grauer D, Proffit WR (2011) Accuracy in tooth positioning with a fully customized lingual orthodontic appliance. Am J Orthod Dentofac Orthop 140(3):433-443

14. Barreto MS, Faber J, Vogel CJ, Araujo TM (2016) Reliability of digital orthodontic setups. Angle Orthod 86(2):255-259

15. Müller-Hartwich R, Jost-Brinkmann P-G, Schubert K (2016) Precision of implementing virtual setups for orthodontic treatment using CAD/CAM-fabricated custom archwires. J Orofac Orthop/ Fortschritte der Kieferorthopädie 77(1):1-8

16. Farronato G, Giannini L, Galbiati G, Pisani L, Mortellaro C, Maspero C (2014) Verification of the reliability of the threedimensional virtual presurgical orthodontic diagnostic protocol. J Craniofac Surg 25(6):2013-2016

17. Macchi A, Carrafiello G, Cacciafesta V, Norcini A (2006) Threedimensional digital modeling and setup. Am J Orthod Dentofac Orthop 129(5):605-610

18. Falter B, Schepers S, Vrielinck L, Lambrichts I, Politis C (2013) Predicted versus executed surgical orthognathic treatment. J Craniomaxillofac Surg 41(7):547-551

19. Kravitz ND, Kusnoto B, BeGole E, Obrez A, Agran B (2009) How well does Invisalign work? A prospective clinical study evaluating the efficacy of tooth movement with Invisalign. Am J Orthod Dentofac Orthop 135(1):27-35

20. Djeu G, Shelton C, Maganzini A (2005) Outcome assessment of Invisalign and traditional orthodontic treatment compared with the American Board of Orthodontics objective grading system. Am J Orthod Dentofac Orthop 128(3):292-298

21. Kuncio D, Maganzini A, Shelton C, Freeman K (2007) Invisalign and traditional orthodontic treatment postretention outcomes compared using the american board of orthodontics objective grading system. Angle Orthod 77(5):864-869

22. Andrews LF (1972) The six keys to normal occlusion. Am J Orthod 62(3):296-309

23. Maes F, Collignon A, Vandermeulen D, Marchal G, Suetens P (1997) Multimodality image registration by maximization of mutual information. IEEE Trans Med Imaging 16(2):187-198

24. Nada RM, Maal TJJ, Breuning KH, Bergé SJ, Mostafa YA, Kuijpers-Jagtman AM (2011) Accuracy and reproducibility of
Voxel based superimposition of cone beam computed tomography models on the anterior cranial base and the zygomatic arches. PLoS One 6(2)

25. Besl PJ, McKay HD (1992) A method for registration of 3-D shapes. IEEE Trans Pattern Anal Mach Intell 14(2):239-256

26. Baan $\mathrm{F}$ et al. (2016) A new 3D tool for assessing the accuracy of bimaxillary surgery: the OrthoGnathicanAlyser. PLoS One 11(2)

27. Choi DS, Jeong YM, Jang I, Jost-Brinkmann PG, Cha BK (2010) Accuracy and reliability of palatal superimposition of threedimensional digital models. Angle Orthod 80(4):497-503

28. Hoggan BR, Sadowsky C (2001) The use of palatal rugae for the assessment of anteroposterior tooth movements. Am J Orthod Dentofac Orthop 119(5):482-488

29. Ganzer N, Feldmann I, Liv P, Bondemark L (2018) A novel method for superimposition and measurements on maxillary digital 3D models - studies on validity and reliability. Eur J Orthod 40(1): 45-51

30. Christou P, Kiliaridis S (2008) Vertical growth-related changes in the positions of palatal rugae and maxillary incisors. Am J Orthod Dentofac Orthop 133(1):81-86

31. Han G, Li J, Wang S, Liu Y, Wang X, Zhou Y (2019) In-vitro assessment of the accuracy and reliability of mandibular dental model superimposition based on voxel-based cone-beam computed tomography registration. Korean J Orthod 49(2):97

32. Park T-J, Lee S-H, Lee K-S (2012) A method for mandibular dental arch superimposition using 3D cone beam CT and orthodontic 3D digital model. Korean J. Orthod. 42(4):169-181

33. Grünheid T, Loh C, Larson BE (2017) How accurate is Invisalign in nonextraction cases? Are predicted tooth positions achieved? Angle Orthod 87(6):809-815

34. Kau CH, Littlefield J, Rainy N, Nguyen JT, Creed B (2010) Evaluation of CBCT digital models and traditional models using the Little's Index. Angle Orthod 80(3):435-439

35. Creed B, Kau CH, English JD, Xia JJ, Lee RP (2011) A comparison of the accuracy of linear measurements obtained from cone beam computerized tomography images and digital models. Semin Orthod 17(1):49-56

36. Lightheart KG et al (2012) Surface analysis of study models generated from OrthoCAD and cone-beam computed tomography imaging. Am J Orthod Dentofac Orthop 141(6):686-693

37. Xi T et al (2017) The effects of surgically assisted rapid maxillary expansion (SARME) on the dental show and chin projection. J Cranio-Maxillofacial Surg 45(11):1835-1841

38. Staggers JA (1994) Vertical changes following first premolar extractions. Am J Orthod Dentofac Orthop 105(1):19-24

39. Pauls AH (2010) Behandlungsgenauigkeit mittels individualisierter brackets in der lingualtechnik. J Orofac Orthop 71(5):348-361

40. Larson BE, Vaubel CJ, Grünheid T (2013) Effectiveness of computer-assisted orthodontic treatment technology to achieve predicted outcomes. Angle Orthod 83(4):557-562

Publisher's note Springer Nature remains neutral with regard to jurisdictional claims in published maps and institutional affiliations. 